\title{
Emission factors and light absorption properties of brown carbon from household coal combustion in China
}

\section{Jianzhong Sun et al.}

Correspondence to: Guorui Zhi (zhigr@ craes.org.cn) and Yingjun Chen (yjchentj@ tongji.edu.cn)

The copyright of individual parts of the supplement might differ from the CC-BY 3.0 licence. 

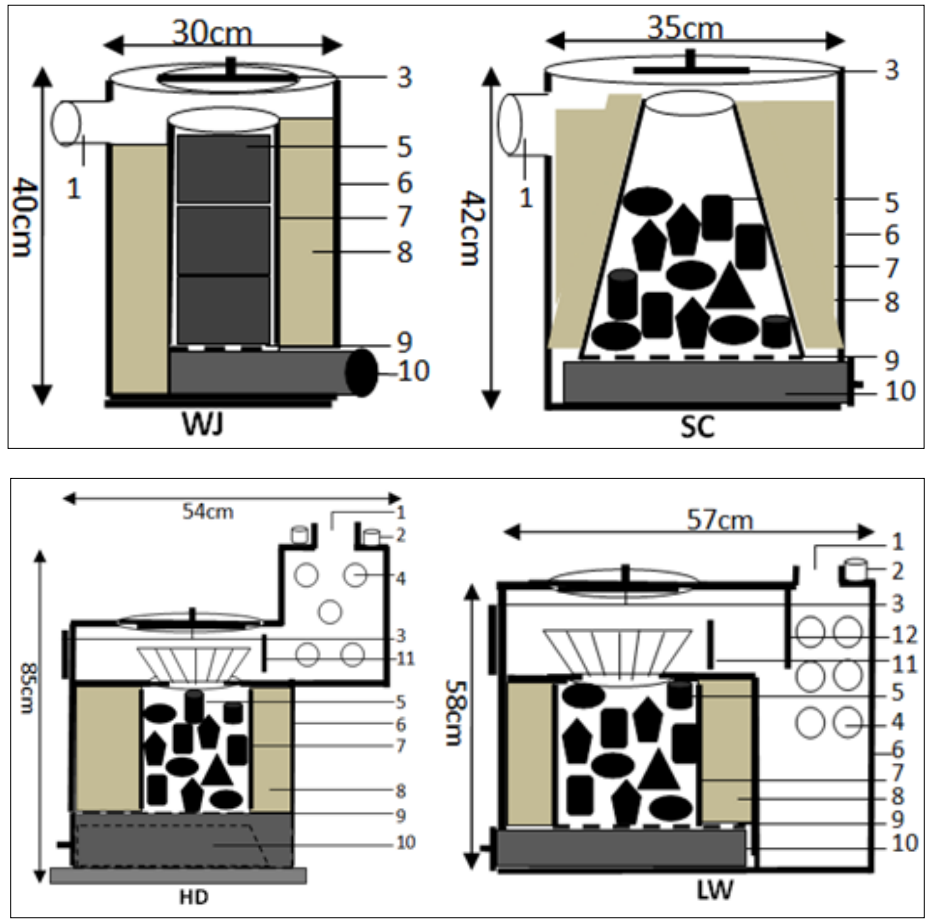

Figure S1. Cross sections of the selected Chinese residential coal-stoves

5 Note: WJ, WanJia brand briquette stove; SC, Simple Chunk stove; HD, HuanDing brand chunk stove; LW, LaoWan brand chunk stove. 1 , metal chimney; 2 , circulation water; 3 , removable lid; 4 , circulation water; 5 , fuel; 6 , iron casting; 7 , ceramic cylinder; 8, ceramic fiber for heating insulation; 9, steel grates; 10, air inlet and/or dust bin; 11, adjustable iron baffle; 12, fixed iron baffle.

Here are the dimensions of all 4 stoves (Chen et al., 2005; Zhi et al., 2008). Among them, WJ is specifically for honeycomb briquettes and the other three (SC, HD, and LW) are for raw-coal chunks. In addition, the briquette stove WJ and chunk stove SC are of traditional style widely used especially in past decades in China's households for heating rooms through direct thermal radiation. HD and LW are actually mini-boilers of low pressure type used for heating rooms by heated water circulating through a piping system $(2,4)$. Compared to HD, the LW stove has an additional iron baffle vertically fixed

15 before the flue pipe so as to lengthen the time of heat exchange between hot flue gas and circulating water. 


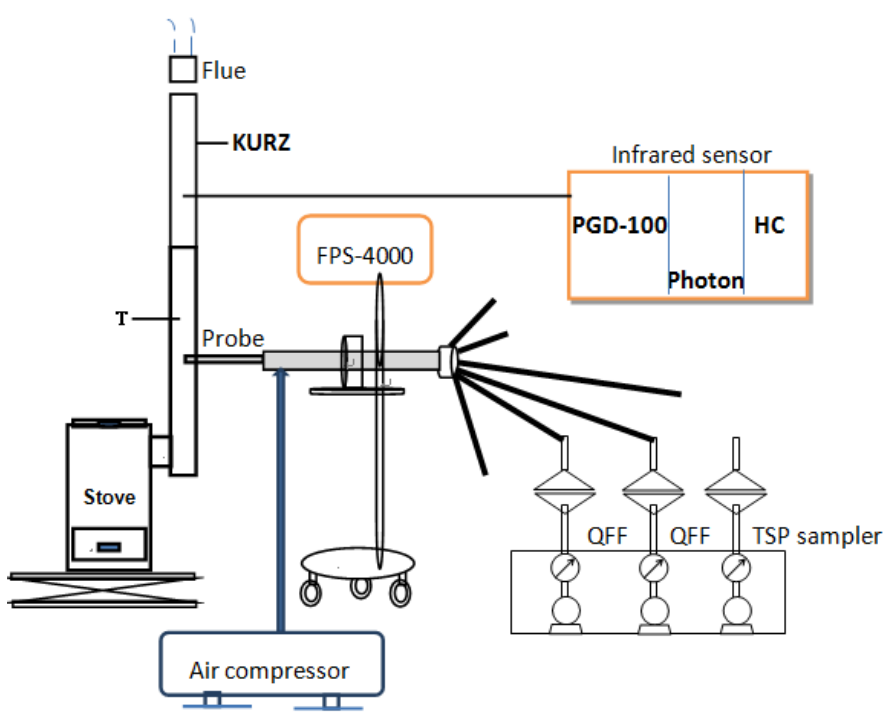

Figure S2. Diversion-dilution-sampling system 
Methods for calculation of EFs (BC and BrC), AAEs, $f_{B r C}(\lambda)$, and $\mathrm{F}_{\mathrm{BrC}}$

\section{(A) EFs}

Each $\mathrm{EF}(\mathrm{g} / \mathrm{kg})$ of BC or BrC can be calculated as follows (Chen et al., 2005; Zhi et al., 2008):

$$
\mathrm{EF}=\mathrm{CF} \times \rho \times \mathrm{A} \times 10^{-6} /((\mathrm{M} 1-\mathrm{M} 2) \times \mathrm{f})
$$

5 Where,

$\mathrm{CF}$ - conversion factor from measured equivalent of carbon black ( $\mathrm{CarB}$ ) to $\mathrm{BC}$ or from measured equivalent of humic acid sodium salt (HASS) to BrC. As described in our manuscript, CF is 1 for the former and is 0.47 for the latter

$\rho$ - the mass of CarB equivalent or HASS equivalent per unit area of sampling filter $\left(\mu \mathrm{g} / \mathrm{cm}^{2}\right)$

A - the area of sampling filter $\left(\mathrm{cm}^{2}\right)$

10 M1 - the mass of coal before combustion $(\mathrm{kg})$

M2 - the mass of coal after combustion $(\mathrm{kg})$

$\mathrm{f}$ - the fraction of sampled flue gas in total flue gas

\section{(B) AAEs}

15 Based on the light absorption at the wavelength pair of 365 and $650 \mathrm{~nm}$ measured by the IS method, AAEs are calculated as follows(Krivácsy et al., 2001; Sun et al., 2007; Lukács et al., 2007; Chen and Bond, 2010; Lack et al., 2013; Yuan et al., 2015; Forrister et al., 2015):

$\mathrm{AAE}=\frac{-\ln (\mathrm{A} 650 / \mathrm{A} 365)}{\ln (650 / 365)}$

\section{(C) $f_{B r C}(\lambda)$ and $F_{B r C}$}

The spectrally dependent absorbance by $\operatorname{BrC}\left(\operatorname{ABS}_{\mathrm{BrC}}(\lambda)\right)$ is obtained by subtracting the $\mathrm{BC}$ absorbance from the total absorbance (Kirchstetter et al., 2012; Chakrabarty et al., 2014):

$$
\operatorname{ABS}_{\mathrm{BrC}}(\lambda)=\operatorname{ABS}_{\text {sum }}(\lambda)-\operatorname{ABS}_{\mathrm{BC}}(\lambda)
$$

Then, in each wavelength, the fraction of $\mathrm{BrC}$ absorbance in total absorbance $\left(\mathrm{f}_{\mathrm{BrC}}(\lambda)\right)$ is calculated as:

$$
\mathrm{f}_{\mathrm{BrC}}(\lambda)=\mathrm{ABS}_{\mathrm{BrC}}(\lambda) / \mathrm{ABS}_{\mathrm{sum}}(\lambda)
$$

Finally, solar spectrum is considered. The average fraction of absorbed solar radiation by $\mathrm{BrC}$ relative to the combined absorption by $\mathrm{BrC}+\mathrm{BC}$ over the wavelength range from 350 to $850 \mathrm{~nm}$

$$
\mathrm{F}_{\mathrm{BrC}}=\frac{\int_{350}^{850} f B r C(\lambda) k(\lambda) \mathrm{d} \lambda}{\int_{350}^{850} k(\lambda) \mathrm{d} \lambda}
$$

Where $\mathrm{k}(\lambda)$ is the clear sky air mass one global horizontal solar spectrum at the earth's surface (Levinson et al., 2010). 
Table S1. Comparison between IS-based $\mathbf{E F}_{\mathrm{BC}}$ and TOR-based $\mathbf{E F}_{\mathrm{EC}}$

\begin{tabular}{lcc}
\hline Coal & \multicolumn{2}{c}{ Chunk (Average voer 3 Chunk stoves) } \\
\hline & EF $_{\text {BC }}$ & EFEC $_{\text {E }}$ \\
\cline { 2 - 3 } NX & 0.26 & 0.12 \\
CZ & 0.59 & 0.29 \\
LL & 5.35 & 4.25 \\
PDS & 10.15 & 8.09 \\
SYS & 8.75 & 10.50 \\
XLZ & 8.81 & 6.80 \\
LK & 6.18 & 4.06 \\
& Briquette (WJ stove) \\
NX & 0.10 & 0.08 \\
CZ & 0.32 & 0.07 \\
LL & 0.41 & 0.27 \\
PDS & 0.86 & 0.41 \\
SYS & 0.68 & 0.80 \\
XLZ & 0.52 & 0.71 \\
LK & 0.31 & 0.21 \\
\hline
\end{tabular}

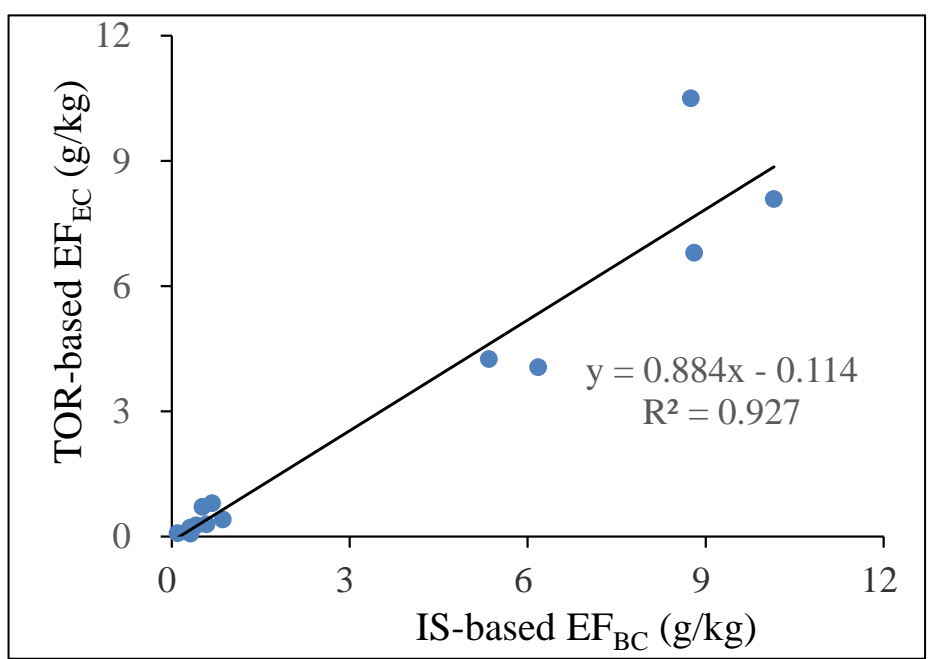

Figure S3. The correlation of EFs between IS-based $\mathbf{E F}_{\mathbf{B C}}$ and TOR-based EFEC 
Table S2. The collection of the directly measured BC (EC) emission factors in our previous article

\begin{tabular}{|c|c|c|c|c|c|}
\hline & & \multicolumn{2}{|c|}{ Anthracite } & \multicolumn{2}{|c|}{ Bituminous } \\
\hline & & Raw chunk & Briquette & Raw chunk & Briquette \\
\hline \multirow{3}{*}{1} & \multirow{3}{*}{$\begin{array}{l}\text { Chen et } \\
\text { al, } 2005\end{array}$} & & 0.004 & & $0.096 \quad 0.675$ \\
\hline & & & & & $\begin{array}{lll}0.523 & 0.064\end{array}$ \\
\hline & & 0.035 & 0.012 & $\begin{array}{lll}0.13 & 0.73\end{array}$ & $0.009 \quad 0.014$ \\
\hline \multirow{3}{*}{2} & \multirow{3}{*}{$\begin{array}{c}\text { Zhi et } \\
\text { al, } 2008\end{array}$} & 0.005 & 0.001 & 16.910 .3 & 0.0760 .016 \\
\hline & & & & 28.54 .35 & $\begin{array}{lll}0.080 & 0.034\end{array}$ \\
\hline & & & & 1.48 & 0.019 \\
\hline \multirow{4}{*}{3} & \multirow{4}{*}{$\begin{array}{c}\text { Chen et } \\
\text { al, } \\
2006\end{array}$} & 0.007 & & 0.205 .34 & \\
\hline & & 0.002 & & 10.1010 .12 & \\
\hline & & & & $12.67 \quad 6.97$ & \\
\hline & & & & 0.48 & \\
\hline \multirow{4}{*}{4} & \multirow{4}{*}{$\begin{array}{l}\text { Chen et } \\
\text { al, } 2015\end{array}$} & 0.02 & 0.06 & 1.71 & 0.67 \\
\hline & & & & 2.38 & 1.3 \\
\hline & & & & 3.46 & 1.28 \\
\hline & & & & 0.61 & 0.07 \\
\hline \multirow{6}{*}{5} & \multirow{8}{*}{$\begin{array}{c}\text { Zhi et } \\
\text { al, } 2009\end{array}$} & & & 0.0420 .51 & $0.011 \quad 0.054$ \\
\hline & & & & $1.23 \quad 2.89$ & 0.0850 .16 \\
\hline & & & & $0.18 \quad 0.083$ & 0.0340 .018 \\
\hline & & & & $0.23 \quad 4.83$ & $0.044 \quad 0.52$ \\
\hline & & & & $10.02 \quad 11.17$ & $0.64 \quad 0.47$ \\
\hline & & & & $\begin{array}{ll}5.77 & 0.55\end{array}$ & $0.31 \quad 0.084$ \\
\hline \multirow{3}{*}{$\begin{array}{c}\text { Mean } \\
\text { sd. }\end{array}$} & & 0.014 & 0.019 & 5.34 & 0.27 \\
\hline & & 0.014 & 0.028 & 6.36 & 0.37 \\
\hline & \multirow{3}{*}{$\begin{array}{l}\text { This } \\
\text { study }\end{array}$} & 0.26 & 0.1 & $5.35 \quad 10.15$ & $0.41 \quad 0.86$ \\
\hline \multirow[t]{2}{*}{6} & & 0.59 & 0.32 & $8.75 \quad 8.81$ & $0.68 \quad 0.52$ \\
\hline & & & & 6.18 & 0.31 \\
\hline \multirow{2}{*}{$\begin{array}{c}\text { Mean } \\
\text { sd. }\end{array}$} & & 0.43 & 0.21 & 7.85 & 0.56 \\
\hline & & 0.23 & 0.16 & 2.00 & 0.22 \\
\hline
\end{tabular}




\section{References}

Chakrabarty, R. K., Pervez, S., Chow, J. C., Watson, J. G., Dewangan, S., Robles, J., and Tian, G.: Funeral pyres in South Asia: Brown carbon aerosol emissions and climate impacts, Environ. Sci. Technol. Lett., 1 (1), 44-48, 10.1021/ez4000669, 2014.

5 Chen, Y. and Bond, T. C.: Light absorption by organic carbon from wood combustion, Atmos. Chem. Phys., 10, 1773-1787, 2010.

Chen, Y., Sheng, G., Bi, X., Feng, Y., Mai, B., and Fu, J.: Emission factors for carbonaceous particles and polycyclic aromatic hydrocarbons from residential coal combustion in China, Environ. Sci. Technol., 39, 1861-1867, 2005.

Chen, Y., Tian, C., Feng, Y., Zhi, G., Li, J., and Zhang, G.: Measurements of emission factors of PM 2.5 , OC, EC, and BC for household stoves of coal combustion in China, Atmos. Environ., 109, 190-196, 10.1016/j.atmosenv.2015.03.023, 2015.

Chen, Y., Zhi, G., Feng, Y., Fu, J., Feng, J., Sheng, G., and Simoneit, B. R. T.: Measurements of emission factors for primary carbonaceous particles from residential raw-coal combustion in China, Geophys. Res. Lett., 33 (20), 1-4, 10.1029/2006gl026966, 2006.

Forrister, H., Liu, J., and Scheuer, E.: Evolution of brown carbon in wildfire plumes: Brown carbon in biomass burning plumes, Geophys. Res. Lett., 42, 1-8, 10.1002/2015GL063897, 2015.

Kirchstetter, T. W. and Thatcher, T. L.: Contribution of organic carbon to wood smoke particulate matter absorption of solar radiation, Atmos. Chem. Phys., 12 (14), 6067-6072, 10.5194/acp-12-6067-2012, 2012.

Krivácsy, Z., Gelencsér, A., Kiss, G., Mészáros, E., Molnár, g., Hoffer, A., Mészáros, T., Sárvári, Z., Temesi, D., and Varga, B.: Study on the chemical character of water soluble organic compounds in fine atmospheric aerosol at the Jungfraujoch, J. Atmos. Chem., 39 (3), 235-259, 10.1023/A:1010637003083, 2001.

Lack, D. A., Bahreni, R., Langridge, J. M., Gilman, J. B., and Middlebrook, A. M.: Brown carbon absorption linked to organic mass tracers in biomass burning particles, Atmos. Chem. Phys., 13 (5), 2415-2422, 2013.

Levinson, R., Akbari, H., and Berdahl, P.: Measuring solar reflectance Part II: Review of practical methods, Solar Energy, 133, 2010.

25 Lukács, H., Gelencsér, A., Hammer, S., Puxbaum, H., Pio, C., Legrand, M., Kasper-Giebl, A., Handler, M., Limbeck, A., Simpson, D., and Preunkert, S.: Seasonal trends and possible sources of brown carbon based on 2-year aerosol measurements at six sites in Europe, J. Geophys. Res., 112 (D23S18), 1-9, 10.1029/2006jd008151, 2007.

Sun, H., Biedermann, L., and Bond, T. C.: Color of brown carbon: A model for ultraviolet and visible light absorption by organic carbon aerosol, Geophys. Res. Lett., 34 (L17813), 1-5, 10.1029/2007g1029797, 2007.

30 Yuan, J. F., Huang, X. F., Cao, L. M., Cui, J., Zhu, Q., Huang, C. N., Lan, Z. J., and He, L. Y.: Light absorption of brown carbon aerosol in the PRD region of China, Atmos. Chem. Phys., 16 (3), 1433-1443, 2016.

Zhi, G., Chen, Y., Feng, Y., Xiong, S., Li, J., Zhang, G., Sheng, G., and Fu, J.: Emission characteristics of carbonaceous particles from various residential coal-stoves in China, Environ. Sci. Technol., 42 (9), 3310-3315, 10.1021/es702247q, 2008. 
Zhi, G., Peng, C., Chen, Y., Liu, D., Sheng, G., and Fu, J.: Deployment of coal briquettes and improved stoves: Possibly an option for both environment and climate, Environ. Sci. Technol., 43 (15), 5586-5591, 10.1021/es802955d, 2009. 